\title{
Commentary: Seeking the grail? Choose wisely
}

\author{
Thomas A. D’Amico, MD
}

\author{
From the Section of General Thoracic Surgery, Duke University Medical Center, Durham, NC. \\ Disclosures: Author has nothing to disclose with regard to commercial support. \\ Received for publication July 17, 2019; revisions received July 17, 2019; accepted for publication July 17, 2019; \\ available ahead of print Oct 10, 2019. \\ Address for reprints: Thomas A. D'Amico, MD, Gary Hock Endowed Professor and Vice-Chair of Surgery, Sec- \\ tion of General Thoracic Surgery, Duke University Medical Center, DUMC Box 3496, Duke South, White \\ Zone, Room 3589, Durham, NC 27710 (E-mail: thomas.damico@ duke.edu). \\ J Thorac Cardiovasc Surg 2020;159:1141 \\ $0022-5223 / \$ 36.00$ \\ Copyright (C) 2019 by The American Association for Thoracic Surgery \\ https://doi.org/10.1016/j.jtcvs.2019.07.141
}

Date's group at Kyoto University Hospital has developed a novel simulation system that generates virtual dynamic images based on patient-specific data from preoperative computed tomographic scans for anatomic pulmonary resection, which they have named the Resection Process Map (RPM). In this group's study in this issue of the Journal, Tokuno and colleagues ${ }^{1}$ retrospectively assessed the usefulness of the system in 18 patients, 9 of whom underwent lobectomy and 9 of whom underwent segmentectomy. The RPM accurately identified $98.6 \%$ of vessel branches and all the bronchi, in a median time of approximately $2 \mathrm{mi}-$ nutes. The results of this pilot analysis are convincing; the videos that accompany the publication are very convincing.

For some surgeons, this system may be considered the holy grail of image-based surgery, surpassing the current systems of intraoperative vessel and nodule localization, computer simulation systems, 3-dimensional optical systems, and 3-dimensional printing in effectively guiding surgeons through anatomic resection. Is this system needed for all lobectomies? Definitely not. Is this system needed for any lobectomy? Not many. Would this system be useful for complex sublobar resections, such as an isolated S-9 or an S-9+10 segmentectomy? Definitely yes. I would wait 2 minutes for an accurate intraoperative map for those operations.

As computed tomographic lung cancer screening reaches its potential worldwide, more and more patients will be identified who might benefit from sublobar resection as opposed to lobectomy. Not all patients with T1a and T1b lung cancer are candidates for sublobar resection, but some are. Precise identification of the location of the nodule and the preoperative assessment of segmental vessel anatomy for planning, with current technology (3-dimensional computed tomographic reconstruction), will become increasingly important. Accurate anatomic representation and precise preoperative planning are only the first step, however, and not all planned sublobar resections are successful; some patients may leave the operating room having many surgeons. wisely.

\section{References} kyo: Springer; 2012.

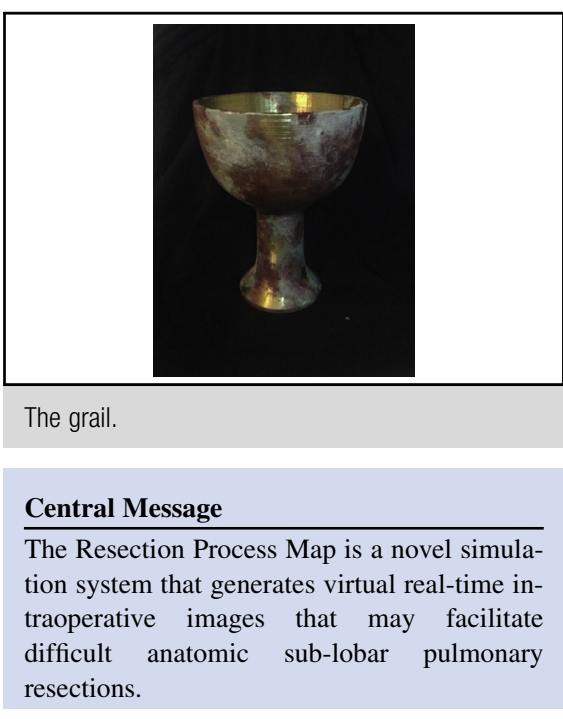

See Article page 1130 .

instead undergone lobectomy (suboptimal in some cases) or a large wedge resection (suboptimal in most cases). The development of technology that will accurately identify $98 \%$ to $100 \%$ of these vessels intraoperatively will greatly facilitate the completion of the precisely planned operation and may greatly facilitate the conduct of the operation for

The RPM system is not, however, a replacement for a deep understanding of segmental anatomy and the conduct of difficult sublobar resections, most effectively written and illustrated by Nomori and Okada. ${ }^{2}$ Date and colleagues plan a prospective evaluation of the RPM system, and it is hoped that they will refine and improve the current technology and demonstrate its utility, to improve globally the successful completion of sublobar resections, when indicated. Nevertheless, I am certain that the surgeons at Kyoto University Hospital would agree that sublobar resection can and should be completed now, in carefully selected patients. Choose

1. Tokuno J, Chen-Yoshikawa TF, Nakao M, Matsuda T, Date H. Resection Process Map: a novel dynamic simulation system for pulmonary resection. J Thorac Cardiovasc Surg. 2020;159:1130-8.

2. Nomori H, Okada M. Illustrated Anatomical Segmentectomy for Lung Cancer. To- 